\title{
Longer time to transfer from the Emergency Department after bed request is associated with worse outcomes
}

Four hour target, time to bed request, mortality.

\author{
Authors \\ Dr Andrew Paton \\ MBChb \\ Adult Retrieval Victoria, Melbourne, Australia \\ Professor Biswadev Mitra \\ Emergency \& Trauma Centre, The Alfred Hospital, Melbourne, Australia \\ National Trauma Research Institute, Monash University, Melbourne, Australia \\ Department of Epidemiology \& Preventive Medicine, Monash University \\ Professor Julie Considine \\ School of Nursing and Midwifery and Centre for Quality and Patient Safety \\ Research, Deakin University, Geelong, Australia \\ Centre for Quality and Patient Safety Research, Eastern Health Partnership
}

\section{Contributorship}

AP planned the study, collected and processed the data, drafted and revised the manuscript. He is the guarantor. BM contributed to the study plan, planned and carried out the stat istical analysis, and revised the draft manuscript. JC contributed to the study plan, statistical analysis plan, and revised the draft manuscript.

Greg Mele of Eastern Health assisted with the initial data collection.

Initial work and data collection performed at Maroondah Hospital, Eastern Health, Ringwood East, Victoria

\section{Corresponding Author}

This is the author manuscript accepted for publication and has undergone full peer review but has not been through the copyediting, typesetting, pagination and proofreading process, which may lead to differences between this version and the Version of Record. Please cite this article as doi: 10.1111/1742-6723.13120

This article is protected by copyright. All rights reserved. 
Dr Andrew Paton

Adult Retrieval Victoria

Address:

75 Brady Street, South Melbourne, Victoria, Australia

Email: Andrew.paton@ambulance.vic.gov.au

Phone: +61390902361

Word count: 2001 (Abstract 249)

\section{Abstract \\ Objective}

To determine the relationships between: i) total Emergency Department length of stay (EDLOS) and in-hospital mortality, ward clinical deterioration; and ii) between time of bed request, ward transfer and in-hospital mortality, with a particular focus on patients transferred just prior to a four-hour EDLOS.

\section{Methods}

Design: Retrospective cohort study using data from three acute care hospitals in Melbourne, Australia.

Participants: Adult patients admitted from the emergency department to a non-monitored ward within 8 hours. Patients were sub-grouped by EDLOS;

EDLOS 3.5-4 hours compared to 0-3.5 hours and 4-8 hours.

Outcomes: In-hospital mortality, number of medical emergency team (MET) / cardiac arrest team (CAT) events.

\section{Results}

This article is protected by copyright. All rights reserved. 
24,746 patients were included: 4,396 patients with EDLOS $<210$ minutes; 4,090 patients with EDLOS of 210-240 minutes; and 16,260 patients with EDLOS $>240$ minutes.

Mortality overall was $2.2 \%(n=545)$, highest mortality was seen with EDLOS $>4$ hours $(2.4 \%, \mathrm{n}=399)$ and lowest in patients with EDLOS $3.5-4$ hours $(1.5 \%$, $\mathrm{n}=63, \mathrm{OR} 0.67(95 \% \mathrm{Cl}: 0.47-0.93, \mathrm{p}=0.02))$. Time from bed request to transfer of $>240$ mins was associated with increased odds of death at hospital discharge (Adjusted OR 1.39 (95\% Cl: 1.08-1.78). There was no difference in rate of MET calls within 24 hours between groups $(3.5-4 \mathrm{hrs}=64(1.5 \%),<3.5$ hrs $=60(1.5 \%), 4-8 \mathrm{hrs}=235(1.4 \%)$.

\section{Conclusions}

Both shorter time in ED and shorter time between bed request and ward transfer were independently associated with improved outcomes. Whole of hospital measures to reduce LOS in the ED should focus on shorter ward transfer times after bed request.

Keywords: NEAT, 4 hour rule, EDLOS, emergency department operations, death/mortality

This article is protected by copyright. All rights reserved. 


\section{Introduction}

Longer ED stay is consistently associated with adverse outcomes including longer inpatient length of stay and higher in-hospital mortality. ${ }^{1,2}$ Four hour Emergency Department length of stay (EDLOS) rules have been implemented in many centres, particularly in the UK and Australia, as a strategy to combat ED overcrowding and improve ED flow and quality of care. ${ }^{3}$ This strategy has usually been part of hospital-wide reforms to improve flow through EDs and inpatient bed access.

Since the introduction of the National Emergency Access Target (NEAT) in Australia, multiple studies have demonstrated improvements in hospital mortality. ${ }^{4,5}$ However, it is not clear whether the in-hospital mortality benefits were directly due to NEAT or as a result of the hospital cultural and infrastructure changes that have occurred to achieve NEAT. Compliance with NEAT targets in some institutions has led to an increased admission rate and resultant lack of inpatient beds ${ }^{6}$; lack of inpatient bed leads to prolonged waits in the ED for admitted patients after their initial management has been completed.

Another concern regarding EDLOS targets is that some patients may be transferred to the ward before they are clinically stable, in particular those patients transferred immediately before reaching the four hour EDLOS time 
limit. ${ }^{7}$ Despite anecdotal concerns about increased medical emergency team activations (MET calls) due to the four-hour rule, this has not been conclusively proven. ${ }^{8}$ Furthermore, there appears to be no significant difference in the proportion of patients with EDLOS less than 4 hours compared with greater than 4 hours who required MET review within the first three days of hospital admission. ${ }^{7}$

We hypothesised that four hour ED discharge rules such as NEAT may lead to clinical deterioration on inpatient wards and increased in-hospital mortality due to transfer when not clinically suitable in order to meet time targets. The primary aim of this study was to determine the association between EDLOS and clinical deterioration or death, with a particular focus on patients transferred just prior to a four-hour EDLOS. Secondary aims were to determine any mortality difference associated with delay between time to bed request and ward transfer.

\section{Methods}

Setting: This was a retrospective cohort study using data from the three acute care sites from a major health service in Melbourne, Australia. Patients admitted via the EDs of the three hospitals during the study period were identified using organisational databases. All MET and cardiac arrest team (CAT) calls for the three hospitals are prospectively logged in a combined 
database managed by the Intensive Care Unit (ICU) liaison team. Ethical approval was obtained from the Eastern Health Human Research Ethics Committee reference number LR71/2015, the need for obtaining consent was waived.

Variables: Variables extracted were patient demographics, EDLOS, time to bed request, time and date of each MET /CAT call, in-hospital deaths.

Inclusion \& exclusion criteria: The study inclusion criteria were adult patients (aged $\geq 18$ years) who were transferred from the ED to an inpatient ward at one of the three acute care sites from 1st July 2013 until $30^{\text {th }}$ March 2015 inclusive. The exclusion criteria were patients who transited through the ED without assessment or management (demonstrated by extremely short time to bed request ( $\leq 15$ minutes) and bed request to transfer times $(<5$ minutes)), patients transferred from the ED to a ward with continuous monitoring such as intensive care, coronary care and high dependency units, and patients admitted to Short Stay Units. Exclusions were based on the premise that these areas are not subject to MET or CAT team activation in the same way as non-monitored inpatient wards. Additionally, determinants of inhospital mortality in critical care units are likely to be severity of disease, and less likely to be influenced by EDLOS. We excluded patients with EDLOS 
greater than 8 hours because prior studies have already established that this is associated with poor outcomes. ${ }^{9}$

Where there was missing data that was key to matching patients across databases attempts were made to recover this information directly from hospital records. Where this was not possible pairwise deletion was conducted for univariate analysis while listwise deletion (complete case analysis) was conducted for multivariable regression analyses.

Included patients were divided into three groups; the exposed group were those transferred just prior to the four hour time limit with EDLOS of $210-240$ minutes (3.5 hours until and including 4 hours). Comparator groups had EDLOS $<210$ minutes ( 3.5 hours) and EDLOS $>240$ minutes ( 4 hours). The primary outcome was in-hospital mortality. Secondary outcomes were MET/CAT calls during the first 24 hours of inpatient stay, total number of MET/CAT calls during inpatient stay, and the relationship between bed request time and ED discharge with respect to in-hospital mortality.

Statistical Analysis: Continuous data were summarised using means (standard deviation). Differences between means between the three subgroups were analysed using one-way analysis of variance (ANOVA). Variables in Table 1 were considered to have clinically significant associations with the exposure variables. Variables that demonstrated a statistically 
significant association with the primary outcome variable of mortality at hospital discharge were entered into a logistic regression model to determine independent associations. Results are presented using adjusted odds ratios with $95 \%$ confidence intervals. A p-value of $<0.05$ was defined to be statistically significant.

In-hospital mortality among this cohort of patients was estimated to be $2.5 \%$. Assuming a clinically significant odds ratio (OR) of 1.6 for mortality to be associated with increased EDLOS as estimated from previous studies, ${ }^{10}$ the minimum number of patients required in each sub-group was estimated to be 4315 , with an alpha of 0.05 and $90 \%$ power.

\section{Results}

Over the study period, there were 84,738 patients admitted to Eastern Health acute care hospitals via the ED. Of these 24,746 met the study inclusion criteria (Figure 1).

\section{Figure 1: Study participants and exclusions}

This article is protected by copyright. All rights reserved. 
There were 4,396 patients with EDLOS less than 210 minutes, 4,090 patients with EDLOS between 210 and 240 minutes and 16,260 patients with an EDLOS greater than 240 minutes. Demographics and ATS triage category are listed in Table 1.

Table 1: Patient demographic and ED arrival data

There were 545 (2.2\%) in-patient deaths in this cohort. In-hospital mortality was highest among patients with EDLOS>240 minutes, with 399 (2.4\%) deaths. There were $63(1.5 \%)$ deaths in patients with EDLOS between 210240 minutes and $83(1.9 \%)$ deaths in patients with EDLOS $<210$ minutes. Time of death for all patients is illustrated in Figure 2. Adjusted odds of death are listed in Table 2, demonstrating that EDLOS between 210-240 minutes was associated with reduced odds of death at hospital discharge compared to patients with EDLOS of $>240$ minutes (OR 0.67 (95\% Cl: 0.47-0.93).

\section{Figure 2. Time of death}

This article is protected by copyright. All rights reserved. 


\section{Table 2. Adjusted odds of death at hospital discharge}

The associations between time to bed request, EDLOS and in-hospital mortality are listed in Table 3. Delays between inpatient bed request and ward transfer were associated with significantly higher in-hospital mortality.

\section{Table 3. Adjusted odds of death at hospital discharge}

There were 677 (4.2\%) MET/CAT calls in patients with EDLOS >240 minutes, 154 (3.8\%) in patients with EDLOS 210-240 minutes and 140 (3.2\%) MET calls among patients with EDLOS $<210$ minutes $(p=0.010)$. The number of MET/CAT calls within 24 hours of admission was 64 (1.5\%), 60 (1.5\%) and $235(1.4 \%)$ respectively for each time period $(p=0.99)$.

\section{Discussion}

Among this cohort of adult patients admitted to the ward, shorter EDLOS was associated with reduced in-hospital mortality. In particular, EDLOS between 210-240 minutes was associated with significantly reduced mortality

This article is protected by copyright. All rights reserved. 
compared to patients with EDLOS > 240 minutes, when adjusted for potential confounders. Earlier times to bed request were not associated with lower inhospital mortality, but rather earlier transfer to ward after bed request was associated with lower mortality. The findings suggest that time limits for EDLOS should be applied to the period of patient journey from inpatient bed request to transfer, and be independent of clinical assessment and management of emergency medical and surgical conditions.

Similar conclusions had been previously reported by Singer et al. who described an increased mortality rate for patients boarded in the ED for more than two hours after finalising their disposition plan. ${ }^{10}$ Further, others have suggested that maximal benefit would be from a four-hour door to inpatient team time and six hour door to ward time, again highlighting that increased time spent in ED after disposition planning was associated with higher risk of adverse outcomes. ${ }^{11}$

The reason for more MET calls and higher in-hospital mortality are unclear . Given that nursing and medical ratios for patients in the ED tend to be more favourable that ward ratios, we propose that this is likely to be due to a delay in access to specialist multi-disciplinary team care rather than a lesser standard of care received in ED. It is also possible that higher disease complexity and / or severity among patients with ED LOS >240 mins were 
unknown confounders, inadequately adjusted for by age and triage category. This may be a possible explanation why disposition of such patients spent longer in ED. This could also be postulated to be an explanation for more MET calls, longer length of stay and higher mortality in this sub-group of patients.

It was reassuring that ward transfer in the 30 minutes prior to the four-hour EDLOS target was not associated with worse outcomes compared to patients discharged prior to 210 minutes. On the contrary, it was associated with improved outcomes when compared to patients with EDLOS $>240$ minutes. These findings mirror previous studies demonstrating that prolonged ED LOS, along with increased ED presentations, is a major cause of ED overcrowding which leads to an increase in waiting times, reduced quality of care, and worsened patient experience as well as poorer outcomes. ${ }^{12,13}$

\section{Limitations}

This study extracted data from three different healthcare sites that have differing models of inpatient admission and assessment; this lends some generalisability to other institutions that employ a four-hour EDLOS targets. The results are limited by the retrospective nature of the data and although some statistical adjustment was possible, a prospective design would help to 
delineate causality rather than association. This study aimed to reduce heterogeneity among the population by excluding patients admitted to critical areas, but it is also possible that unknown confounders of disease severity may alter the results.

\section{Conclusions}

This study has once again demonstrated beneficial effects of NEAT but generates the hypothesis that effects of NEAT can be further augmented by a focus towards time from bed request to ward transfer. The study results suggest that the benefits associated with NEAT may be due to rapid ward transfer after bed request, which depends on inpatient bed availability. Focus on inpatient bed availability may remove potential harm from rushed decisions, while retaining the benefits of reduced EDLOS. Future prospective studies are required to determine if this association is directly due to time spent in ED after bed request, or a delay in access to specialty team care. 


\section{Competing interests}

We have read and understood EMA policy on declaration of interests and

declare that we have no competing interests.

\section{Acknowledgments}

The authors would like to thank Dr Greg Mele of Eastern Health for his assistance with data collection.

No funding was obtained for the purposes of this study.

\section{REFERENCES}

1. Liew D LD, Kennedy MP. Emergency department length of stay independently predicts excess inpatient length of stay. Med J Aust. 2003;179:524-6.

2. Richardson DB. Increase in patient mortality at 10 days associated with emergency department overcrowding. Med J Aust. 2006;184(5).

3. COAG. Expert Panel Review of Elective Surgery and Emergency Access Targets under the National Partnership Agreement on Improving Public Hospital Services Australian Government 2011 [Available from: http://www.coag.gov.au/sites/default/files/Expert Panel Report D0490.pdf. 4. Sullivan CM, Staib A, Flores J, Aggarwal L, Scanlon A, Martin JH, et al. Aiming to be NEAT: safely improving and sustaining access to emergency care in a tertiary referral hospital. Aust Health Rev. 2014;38(5):564-74.

5. Geelhoed GC, de Klerk NH. Emergency department overcrowding, mortality and the 4-hour rule in Western Australia. Med J Aust. 2012;196(2):122-6.

6. Perera ML, Davies AW, Gnaneswaran N, Giles M, Liew D, Ritchie P, et al. Clearing emergency departments and clogging wards: National Emergency Access Target and the law of unintended consequences. Emerg Med Australas. 2014;26(6):549-55.

7. Considine J, Jones D, Pilcher D, Currey J. Patient physiological status during emergency care and rapid response team or cardiac arrest team activation during early hospital admission. Eur J Emerg Med. 2016;Publish Ahead of Print.

8. van Heerden P, Blott J, Pinder M, Cameron P, Roberts B, Brinkworth A, et al. Intensive care unit occupancy after introduction of the emergency department

This article is protected by copyright. All rights reserved. 
4-hour discharge rule at a tertiary referral hospital in Western Australia. Crit Care Resusc. 2013;15(4):318-21.

9. Forero R HK. Access Block And Overcrowding: A Literature Review. In: ACEM, editor. 2008. p. 27.

10. Singer AJ, Thode HC, Jr., Viccellio P, Pines JM. The association between length of emergency department boarding and mortality. Acad Emerg Med. 2011;18(12):1324-9.

11. Plunkett PK, Byrne DG, Breslin T, Bennett K, Silke B. Increasing wait times predict increasing mortality for emergency medical admissions. Eur J Emerg Med. 2011;18(4):192-6.

12. Richardson D, Mountain D. Myths versus facts in emergency department overcrowding and hospital access block. Med J Aust. 2009;190(7):369-74.

13. Richardson D. The access-block effect- relationship between delay to reaching an inpatient bed and inpatient length of stay. Med J Aust.

2002;177(9):492-5.

This article is protected by copyright. All rights reserved. 
Table 1: Patient demographic and ED arrival data

\begin{tabular}{|c|c|c|c|c|}
\hline & \multicolumn{3}{|c|}{ Time in ED (mins) } & \multirow[b]{2}{*}{$p$-value } \\
\hline & $\begin{array}{c}0-209 \\
(\mathrm{~N}=4396)\end{array}$ & $\begin{array}{l}210-240 \\
(\mathrm{~N}=4090)\end{array}$ & $\begin{array}{c}241-480 \\
(\mathrm{~N}=16,260)\end{array}$ & \\
\hline $\begin{array}{l}\text { Male Gender } \\
\text { (\%) }\end{array}$ & $\begin{array}{c}2262 \\
(51.5 \%)\end{array}$ & $\begin{array}{c}1963 \\
(48.0 \%)\end{array}$ & $\begin{array}{c}7681 \\
(47.2 \%)\end{array}$ & $<0.001$ \\
\hline $\begin{array}{l}\text { Age (years), } \\
\text { mean (SD) }\end{array}$ & $56.1(22.5)$ & $61.7(22.1)$ & $63.0(21.7)$ & 0.003 \\
\hline $\begin{array}{r}\text { ATS category, \% } \\
(n)\end{array}$ & & & & $<0.001$ \\
\hline 1 & $71(1.6 \%)$ & $30(0.7 \%)$ & $132(0.8 \%)$ & \\
\hline 2 & $994(22.6 \%)$ & $759(18.6 \%)$ & $2809(17.3 \%)$ & \\
\hline 3 & $2096(47.7 \%)$ & $1995(48.8 \%)$ & $8212(50.5 \%)$ & \\
\hline 4 & $1037(23.6 \%)$ & $1170(28.6 \%)$ & $4553(28.0 \%)$ & \\
\hline 5 & $58(1.3 \%)$ & $48(1.2 \%)$ & $166(1.0 \%)$ & \\
\hline $\begin{array}{l}\text { Ambulance } \\
\text { transport to the } \\
\text { ED }\end{array}$ & $1895(43.1 \%)$ & $\begin{array}{c}1895 \\
(46.3 \%)\end{array}$ & $\begin{array}{c}7962 \\
(49.0 \%)\end{array}$ & $<0.001$ \\
\hline $\begin{array}{l}\text { Residing at } \\
\text { home }\end{array}$ & $3930(89.4 \%)$ & $3627(88.7 \%)$ & $\begin{array}{c}14181 \\
(87.2 \%)\end{array}$ & 0.013 \\
\hline
\end{tabular}

Table 2. Adjusted odds of death at hospital discharge

\begin{tabular}{|l|l|l|}
\hline Variable & OR $\mathbf{( 9 5 \% ~ C l )}$ & p-value \\
\hline Age (years) & $1.05(1.04-1.06)$ & $<0.001$ \\
\hline Male gender & $1.19(0.99-1.42)$ & 0.051 \\
\hline ED LOS >240 mins & Reference & \\
\hline ED LOS 210-240 mins & $0.67(0.47-0.93)$ & 0.020 \\
\hline ED LOS <210 mins & $1.06(0.82-1.35)$ & 0.660 \\
\hline Triage Cat 1 & Reference & \\
\hline Triage Cat 2 & $0.31(0.21-0.47)$ & $<0.001$ \\
\hline Triage Cat 3 & $0.16(0.11-0.24)$ & $<0.001$ \\
\hline Triage Cat 4 & $0.11(0.07-0.17)$ & $<0.001$ \\
\hline Triage Cat 5 & $0.18(0.06-0.52)$ & 0.002 \\
\hline Ambulance transport & $1.91(1.49-2.43)$ & $<0.001$ \\
\hline
\end{tabular}




\begin{tabular}{|l|l|l|}
\hline Residing at home & $0.62(0.50-0.76)$ & $<0.001$ \\
\hline
\end{tabular}

Table 3. Adjusted odds of death at hospital discharge

\begin{tabular}{|l|l|l|}
\hline Variable & OR $(\mathbf{9 5} \% \mathbf{C l})$ & p-value \\
\hline Age (years) & $1.05(1.04-1.06)$ & $<0.001$ \\
\hline Male gender & $1.20(1.01-1.43)$ & 0.045 \\
\hline & & \\
\hline Time to bed request $\mathbf{1 2 0}$ mins & Reference & \\
\hline Time to bed request 121-180 mins & $0.99(0.79-1.22)$ & 0.910 \\
\hline Time to bed request 181-240 mins & $0.96(0.74-1.25)$ & 0.763 \\
\hline Time to bed request $\mathbf{2 4 0}$ mins & $0.90(0.63-1.29)$ & 0.560 \\
\hline & & \\
\hline $\begin{array}{l}\text { Time from bed request to ward } \\
\text { transfer } \mathbf{1 2 0} \text { mins }\end{array}$ & Reference & \\
\hline $\begin{array}{l}\text { Time from bed request to ward } \\
\text { transfer 121-180 mins }\end{array}$ & $1.23(0.96-1.56)$ & 0.100 \\
\hline $\begin{array}{l}\text { Time from bed request to ward } \\
\text { transfer 181-240 mins }\end{array}$ & $1.36(1.05-1.77)$ & 0.022 \\
\hline $\begin{array}{l}\text { Time from bed request to ward } \\
\text { transfer } \mathbf{2 4 0} \text { mins }\end{array}$ & $1.39(1.08-1.78)$ & 0.015 \\
\hline & & \\
\hline Triage Category 1 & Reference & \\
\hline Triage Category 2 & $0.31(0.21-0.47)$ & $<0.001$ \\
\hline Triage Category 3 & $0.17(0.11-0.25)$ & $<0.001$ \\
\hline Triage Category 4 & $0.12(0.07-0.18)$ & $<0.001$ \\
\hline Triage Category 5 & $0.18(0.06-0.55)$ & 0.002 \\
\hline & & \\
\hline Ambulance transport & $1.88(1.47-2.40)$ & $<0.001$ \\
\hline Residing at home & $0.62(0.50-0.76)$ & $<0.001$ \\
\hline & & \\
\hline
\end{tabular}

Figure 1: Study participants and exclusions

Figure 2. Time of death 


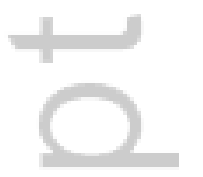

This article is protected by copyright. All rights reserved. 
Kaplan-Meier survival estimates

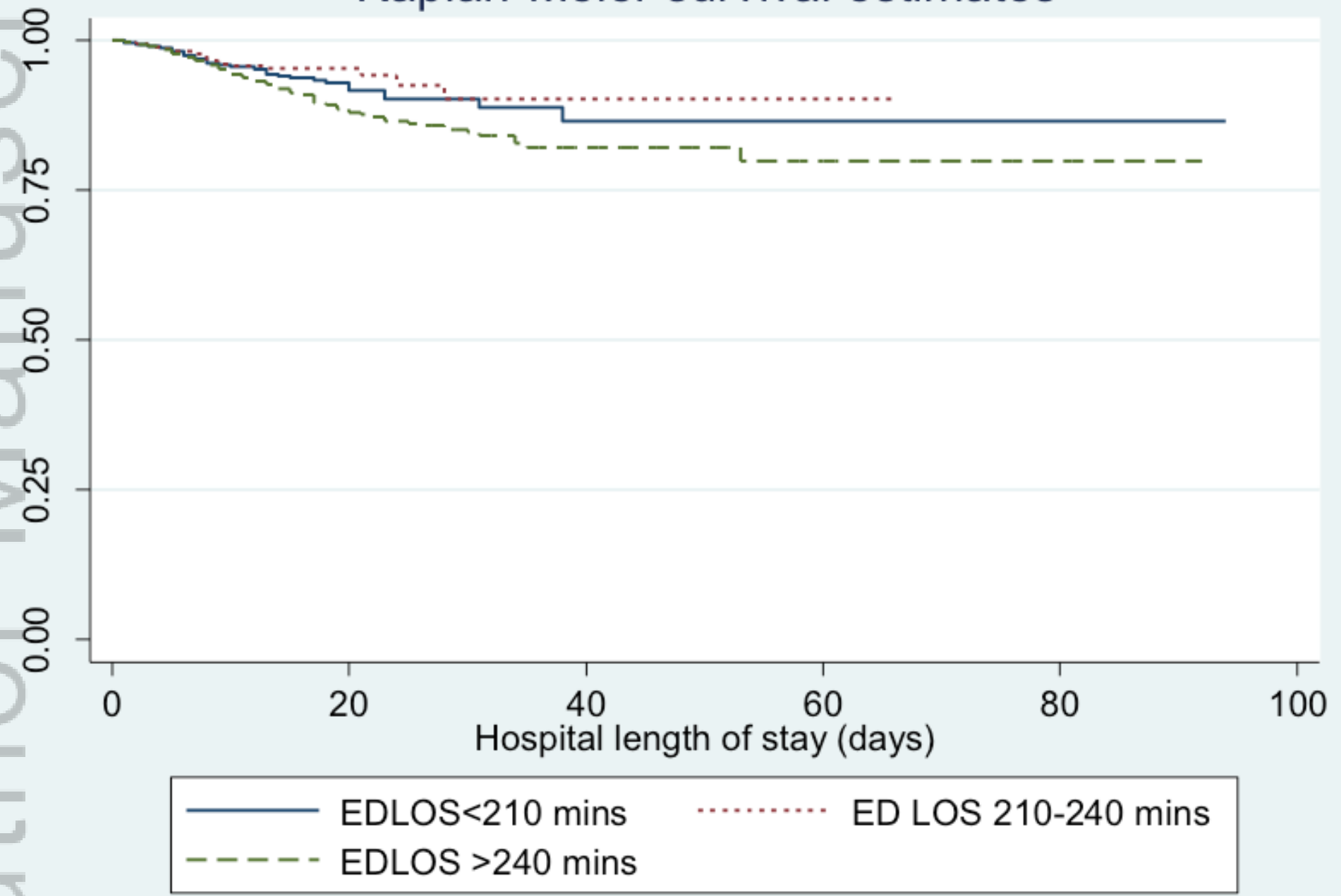

fig 2.png 


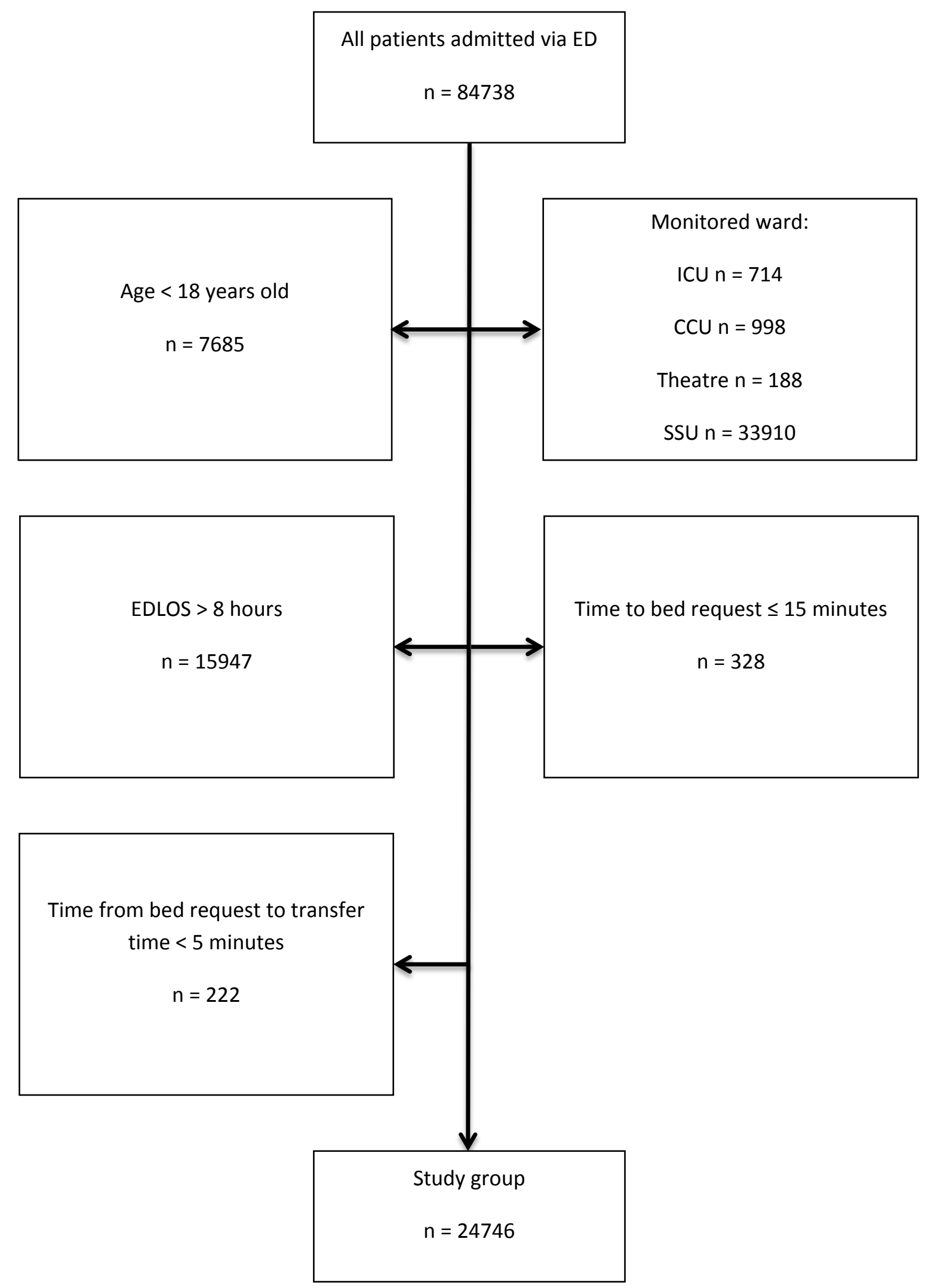

This article is protected by copyright. All rights reserved. 


\title{
Longer time to transfer from the Emergency Department after bed request is associated with worse outcomes
}

Four hour target, time to bed request, mortality.

\author{
Authors \\ Dr Andrew Paton \\ MBChb \\ Adult Retrieval Victoria, Melbourne, Australia \\ Professor Biswadev Mitra \\ Emergency \& Trauma Centre, The Alfred Hospital, Melbourne, Australia \\ National Trauma Research Institute, Monash University, Melbourne, Australia \\ Department of Epidemiology \& Preventive Medicine, Monash University \\ Professor Julie Considine \\ School of Nursing and Midwifery and Centre for Quality and Patient Safety \\ Research, Deakin University, Geelong, Australia \\ Centre for Quality and Patient Safety Research, Eastern Health Partnership
}

\section{Contributorship}

AP planned the study, collected and processed the data, drafted and revised the manuscript. He is the guarantor. BM contributed to the study plan, planned and carried out the statistical analysis, and revised the draft manuscript. JC contributed to the study plan, statistical analysis plan, and revised the draft manuscript.

Greg Mele of Eastern Health assisted with the initial data collection.

Initial work and data collection performed at Maroondah Hospital, Eastern Health, Ringwood East, Victoria

\section{Corresponding Author}

Dr Andrew Paton

Adult Retrieval Victoria

Address:

75 Brady Street, South Melbourne, Victoria, Australia

Email: Andrew.paton@ambulance.vic.gov.au

Phone: +61 390902361

Word count: 2001 (Abstract 249) 


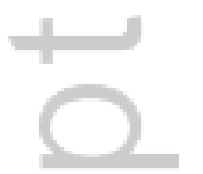

4 


\section{University Library}

\section{- M M N E R VA A gateway to Melbourne's research publications}

Minerva Access is the Institutional Repository of The University of Melbourne

Author/s:

Paton, A;Mitra, B;Considine, J

Title:

Longer time to transfer from the emergency department after bed request is associated with worse outcomes.

Date:

2019-04

Citation:

Paton, A., Mitra, B. \& Considine, J. (2019). Longer time to transfer from the emergency department after bed request is associated with worse outcomes.. Emerg Med Australas, 31 (2), pp.211-215. https://doi.org/10.1111/1742-6723.13120.

Persistent Link:

http://hdl.handle.net/11343/285194 